\title{
Osteoarthritis in southeast Asia
}

\begin{abstract}
"Preliminary data show that the prevalence of osteoarthritis of the knee in some southeast Asian populations is as high as in Caucasian populations ... Therefore, there is an urgent need for population-based studies to better assess the burden of the disease and its risk factors."
\end{abstract}

Keywords: osteoarthritis $\bullet$ osteoarthritis of the knee $\bullet$ osteoarthritis of the spine $\bullet$ southeast Asia $\bullet$ urbanization

\section{Osteoarthritis}

Osteoarthritis (OA) is a multifactorial and complex disease that involves change in articular bone and cartilage structure. The multifactorial nature of $\mathrm{OA}$ is that the disease is not a single entity, but encompasses many entities, including the the loss of cartilage within synovial joints, hypertrophy of bone, and thickening of the capsule. The complexity is in the causality and etiology of the disease as its risk is determined by multiple, and probably interactive, effects of genetic and environmental factors. A reasonable definition that can capture the complexity and multifactorial nature of the disease is "a heterogeneous group of conditions that lead to joint symptoms and signs, which are associated with defective integrity of of cartilage, in addition to related changes in the underlying bone at the joint margins" [1]. Although OA can affect any joint in the body, it is often found at the hands, knees, hips, and spine.

A challenge in studies of $\mathrm{OA}$ is in the diagnosis. There is a considerable disparity between clinical and radiologic diagnoses. There are many radiologic methods for diagnosing OA, but the Empire Rheumatism Council system of grading first described by Kellgren and Lawrence [2] is probably the most widely used scale in epidemiologic studies. The Kellgren-Lawrence method is actually a system of OA grading based on the presence or absence of osteophytes, joint space narrowing, subchondral sclerosis, and bony cysts. In an epidemiologic study, it was noted that while the prevalence of clinically diagnosed knee OA was approximately $18 \%$, the radiologically based method identified $25-30 \%$ [3]. The degree of diagnostic agreement of between clinical diagnosis and radiologic diagnosis was moderate [3], which was confirmed by a recent meta-analysis [4].

However, with recent advances in imaging technology (e.g., MRI), there has been a shift in thinking about OA. Instead of being viewed as a 'tear and wear' disease, OA is now viewed as an active disease with disruption in processes involved in the maintenance of healthy cartilage [5]. Nevertheless, image-based diagnosis of OA has not been widely used in research studies [5].

\section{Prevalence of OA}

$\mathrm{OA}$ is the most common musculoskeletal disorder among the elderly, and women are more likely to be affected than men. A population-based analysis based on NHES survey data found that the prevalence of hand OA was $29.5 \%$ among those aged 25 years and older [6]. A recent analysis of NHANES III data found that approximately $35 \%$ of women and men aged 60 years and above had radiographic OA of the knee [7]. In a Chinese population aged $\geq 60$ years, the prevalence of knee OA was $22 \%$ in men and $43 \%$ in women, and this prevalence was $45 \%$ higher than that in the US white population [8]. In a Japanese rural population, the prevalence of knee OA was $30 \%$ in women and $11 \%$ in men.

Surprisingly, the prevalence of spinal OA has not been well documented. Based on a few studies in the literature, it seems that the prevalence varies remarkably between
Tuan V Nguyen

Osteoporosis \& Bone Biology Division, Garvan Institute of Medical Research, School of Public Health Community Medicine, University of New South Wales, Centre for Health Technologies, University of Technology, Sydney, Australia

and

Bone \& Muscle Research Division, Faculty of Applied Sciences, Ton Duc Thang University, Vietnam

Tel.: +61292958277

Fax: +61292958241

t.nguyen@garvan.org.au 
populations depending on age and sex of participants, method of ascertainment used, and the specificity of joint sites [9]. A retrospective study found that the prevalence of spinal OA was as high as $80 \%$ among Caucasian individuals aged 40 years and older [10]. However, in a study on elderly individuals in a Japanese village [11], $42 \%$ of men and $36 \%$ of women had radiographic OA of the spine.

\section{Southeast Asia}

Southeast Asia consists of 11 countries that lie between China and the Indian subcontinent. The region is highly diverse in terms of economic development and population characteristics. While Brunei and Singapore are well-off economically, other countries such as Malaysia, Thailand, Indonesia and the Philippines are relatively better-off. Vietnam, Cambodia, Laos and Myanmar are considered small economies and are in a state of transition from centrally planned to market economies. The total population of southeast Asia in 2010 was 593 million, which was $8.6 \%$ of the global population. Like most developing parts of the world, the population in southeast Asia has been steadily increasing. Within 28 years (since 1972), the southeast Asian population has doubled.

"...31\% of men and $35 \%$ of women had radiographic osteoarthritis of the knee ... These figures ... suggest that the prevalence of knee osteoarthritis in southeast Asia is comparable with Japanese and Caucasian populations."

Despite the sizeable population and diversity, basic data on the prevalence of radiographic OA are surprisingly unavailable in many southeast Asian countries. There are no prevalence data for Singapore, Malaysia, Myanmar, Indonesia, the Philippines, Cambodia and Laos. During the past 8 years or so, only two published studies have investigated the prevalence of OA in Thailand and Vietnam. In 2006, a study on the prevalence of knee OA among 267 male Thai monks [12] aged 40-79 years, almost $60 \%$ had knee OA. A second population-based epidemiological study was conducted in Vietnam, which involved 170 men and 488 women aged greater than 40 years, in which the investigators found that $31 \%$ of men and $35 \%$ of women had radiographic OA of the knee [13]. Both studies used the Kellgren-Lawrence criteria for the diagnosis of OA. These figures, taken together, suggest that the prevalence of knee OA in southeast Asia is comparable with Japanese [14] and Caucasian populations [7].

The burden of OA in southeast Asia, as in other developing parts of the world, is expected to increase in the coming decades. The increase can be seen via the expected changes in risk factor for OA. Risk factors for OA of the knee have been systematically reviewed [15], and they include advancing age, high BMI, smoking, and lack of physical activity. These risk factors are relevant to southeast Asian countries because they can explain the rise of OA burden in the region.

\section{"...self-reported knee complaints are highly associated with knee osteoarthritis: pain when squatting, bony enlargement and crepitus."}

At present, southeast Asia is experiencing two major demographic transitions: the aging of population, and the urbanization. Data from the UN Population Division [16] indicate that in 2000, southeast Asia had 24.5 million people aged 60 years and above (i.e., 'older population'), which was approximately $4.7 \%$ of the total population. The number of older people was projected to double in $2025,8.4 \%$ of total population. However, the rate of population aging varied greatly between countries within the region, with Singapore having the oldest population, and Cambodia having the youngest population in southeast Asia.

With the region, the pace of urbanization has been widely varied between countries. The proportion of population living in urban areas is $100 \%$ in Singapore, $72 \%$ in Brunei, but is much lower in Laos and Vietnam (27-28\%). Overall, in 2010, approximately $42 \%$ of the southeast Asian population lived in urban areas, which represents a twofold increase from 1970. It is projected that by 2030 , approximately $53 \%$ of the population will live in urban areas. However, the rate of urbanization is highly variable between countries, with a high rate being observed in Vietnam, Malaysia, and Thailand, and lower rates being found in Cambodia, Myanmar and Laos.

The population aging and urbanization will account for the increase in OA prevalence in southeast Asia. Population aging will increase the proportion and the number of elderly people in the community. Urbanization is associated with reduced physical activity [17], which is in turn associated with an increased risk of OA [15].

Moreover, at the population level, urbanization is also an ecologic risk factor for obesity. People living in urban areas may have a comfortable life, but they also use more high calorie foods from multinational food supply chains [18], more passive transportation [19]. Fast food outlets are becoming common in major cities in southeast Asian countries. In less than a generation southeast Asia has transformed itself from active to sedentary lifestyle, with motorcycles and cars replacing bicycles. The dependence on processed food and lack of physical activity all contribute to the rise in the 
prevalence of obesity. A recent analysis found that the age-adjusted prevalence of obesity (defined as BMI $\geq 25 \mathrm{~kg} / \mathrm{m}^{2}$ ) was as high as $62 \%$ in Brunei, $40-42 \%$ in Thailand and Malaysia. The prevalence was lower in Vietnam (12\%; Singapore: 27\%) [20].

In a recent study of OA of the knee, we found that self-reported knee complaints are highly associated with knee OA: pain when squatting, bony enlargement and crepitus. In Asia, people have the habit of squatting or sitting on the floor, and it has been postulated that squatting may in fact protect against $\mathrm{OA}$ of the hip [29], and help reduce knee OA. Thus, pain when squatting appears to be a good indication of knee OA.

"...urbanization is rapidly increasing and more individuals take sedentary work, it is expected that obesity and hence osteoarthritis in southeast

Asia are not only to increase, but also impact those in the lower socioeconomic status."

It is of interest to note that in developing countries people in the lower socioeconomic status often have lower rate of obesity, but in the developed world the opposite is true. However, as urbanization is rapidly increasing and more individuals take sedentary work, it is expected that obesity and hence OA in southeast Asia are not only to increase, but also impact those in the lower socioeconomic status.

It is the clinical and economic impacts of OA on the population that are of concern in the future. OA is associated with pain, disability, and reduced life expectancy. OA is a major cause of musculoskeletal pain/ complaints. Studies in European populations have reported that the prevalence of musculoskeletal pain ranged between 30 and $80 \%$ [21-23]. In Australia, OA is the third largest cause of life-years lost due to disability, and this impact is equal to that of asthma [24]. In Singapore, the cost of OA treatment varied considerably between patients. Among those without surgery, the direct average cost was SGD\$1459; however, the cost was higher among those with knee replacement therapy (SGD \$5561) or hip replacement therapy (SGD \$7555) [25]. Thus, given the rise in the aging population, $\mathrm{OA}$ is

\section{References}

1 Altman R, Asch E, Bloch D et al. Development of criteria for the classification and reporting of osteoarthritis. Classification of osteoarthritis of the knee. Diagnostic and Therapeutic Criteria Committee of the American Rheumatism Association. Arthritis Rheum. 29, 1039-1049 (1986)

2 Kellgren JH, Lawrence JS. Radiological assessment of rheumatoid arthritis. Ann. Rheum. Dis. 16, 485-493 (1957). likely to impose a significant burden to the healthcare system in the southeast Asian countries.

\section{Conclusion}

It is clear that $\mathrm{OA}$ is a growing public health problem in southeast Asia. Preliminary data show that the prevalence of $\mathrm{OA}$ of the knee in some southeast Asian populations is as high as in Caucasian populations. However, there is a dearth of data concerning the prevalence and risk factors for OA of the spine, hips and hands. Therefore, there is an urgent need for population-based studies to better assess the burden of the disease and its risk factors.

The diagnosis of OA has largely been based on the standard radiograph examination, which commonly identifies late-stage disease. Plain radiography is often insufficient for assessing the progression of $\mathrm{OA}$ in a short timeframe. Recent evidence have suggested that a combination of multiple biomarkers and clinical risk factors could improve the detection and prediction of radiographic changes in OA [26-28]. The development of such predictive models is highly relevant for southeast Asian populations. However, such models can only be developed from well-designed population based studies, which are lacking in the region.

It is a truism that OA research has not received serious attention from southeast Asian clinicians who sometimes consider that the disease is 'boring'. However, with the projected increase in the burden of OA in southeast Asia and recent advances in medical and genomic technologies, OA research will be a challenging and much more rewarding to clinicians and scientists.

\section{Financial \& competing interests disclosure}

The author has no relevant affiliations or financial involvement with any organization or entity with a financial interest in or financial conflict with the subject matter or materials discussed in the manuscript. This includes employment, consultancies, honoraria, stock ownership or options, expert testimony, grants or patents received or pending, or royalties.

No writing assistance was utilized in the production of this manuscript. 
6 Lawrence RC, Helmick CG, Arnett FC et al. Estimates of the prevalence of arthritis and selected musculoskeletal disorders in the United States. Arthritis Rheum. 41, 778-799 (1998).

7 Nguyen US, Zhang Y, Zhu Y et al. Increasing prevalence of knee pain and symptomatic knee osteoarthritis: survey and cohort data. Ann. Intern. Med. 155, 725-732 (2011).

8 Zhang Y, Xu L, Nevitt MC et al. Comparison of the prevalence of knee osteoarthritis between the elderly Chinese population in Beijing and whites in the United States: the Beijing Osteoarthritis Study. Arthritis Rheum. 44, 2065-2071 (2001).

9 Battie MC, Videman T, Parent E. Lumbar disc degeneration epidemiology and genetic influences. Spine (Phila Pa 1976) 29, 2679-2690 (2004)

10 Kramer PA. Prevalence and distribution of spinal osteoarthritis in women. Spine (Phila Pa 1976) 31, 2843-2848 (2006).

11 Horikawa K, Kasai Y, Yamakawa T, Sudo A, Uchida A Prevalence of osteoarthritis, osteoporotic vertebral fractures, and spondylolisthesis among the elderly in a Japanese village. J. Orthop. Surg. (Hong Kong) 14, 9-12 (2006).

12 Tangtrakulwanich B, Geater AF, Chongsuvivatwong V. Prevalence, patterns, and risk factors of knee osteoarthritis in Thai monks. J. Orthop. Sci. 11, 439-445 (2006).

13 Ho-Pham LT, Lai TQ, Mai LD et al. Prevalence of radiographic osteoarthritis of the knee and its relationship to self-reported pain. PLoS ONE 9(4), e94563 (2014).

14 Muraki S, Oka H, Akune T et al. Prevalence of radiographic lumbar spondylosis and its association with low back pain in elderly subjects of population-based cohorts: the ROAD study. Ann. Rheum. Dis. 68, 1401-1406 (2009).

15 Blagojevic M, Jinks C, Jeffery A, Jordan KP. Risk factors for onset of osteoarthritis of the knee in older adults: a systematic review and meta-analysis. Osteoarthritis Cartilage 18, 24-33 (2010).

16 United Nations, Department of Economic and Social Affairs, Population Division. World Population Prospects: The 2012 Revision, Key Findings and Advance Tables. Working Paper No. ESA/P/WP.227 (2013).

17 Monda KL, Gordon-Larsen P, Stevens J, Popkin BM. China's transition: the effect of rapid urbanization on adult occupational physical activity. Soc. Sci. Med. 64, 858-870 (2007)
18 Reardon T, Timmer CP, Barrett CB, Berdegué J. The rise of supermarkets in Africa, Asia, and Latin America. Am. J. Agr Econ. 85, 1140-1146 (2003).

19 Kjellstrom T, Hakansta C, Hogstedt C. Globalisation and public health-overview and a Swedish perspective. Scand. J. Public Health Suppl. 70, 2-68 (2007).

20 Dans A, Ng N, Varghese C et al. The rise of chronic noncommunicable diseases in southeast Asia: time for action. Lancet 377, 680-689 (2011)

21 Donald IP, Foy C. A longitudinal study of joint pain in older people. Rheumatology (Oxford) 43, 1256-1260 (2004).

22 Miro J, Paredes S, Rull M et al. Pain in older adults: a prevalence study in the Mediterranean region of Catalonia. Eur. J. Pain 11, 83-92 (2007).

23 Thomas E, Peat G, Harris L, Wilkie R, Croft PR. The prevalence of pain and pain interference in a general population of older adults: cross-sectional findings from the North Staffordshire Osteoarthritis Project (NorStOP). Pain 110, 361-368 (2004)

24 March LM, Bachmeier CJ. Economics of osteoarthritis: a global perspective. Baillieres Clin. Rheumatol. 11, 817-834 (1997).

25 Xie F, Thumboo J, Fong KY et al. Direct and indirect costs of osteoarthritis in Singapore: a comparative study among multiethnic Asian patients with osteoarthritis. J. Rheumatol. 34, 165-171 (2007).

26 Hunter DJ, Losina E, Guermazi A et al. A pathway and approach to biomarker validation and qualification for osteoarthritis clinical trials. Curr. Drug Targets 11, 536-545 (2010).

27 Cibere J, Zhang H, Garnero P et al. Association of biomarkers with pre-radiographically defined and radiographically defined knee osteoarthritis in a populationbased study. Arthritis Rheum. 60, 1372-1380 (2009).

28 Dam EB, Loog M, Christiansen C et al. Identification of progressors in osteoarthritis by combining biochemical and MRI-based markers. Arthritis Res. Ther. 11, R115 (2009).

29 Gunn D. Squatting and osteoarthritis of the hip. Proceedings of British Orthopaedic Association. J. Bone Joint Surg. 46B, 156 (1964). 